


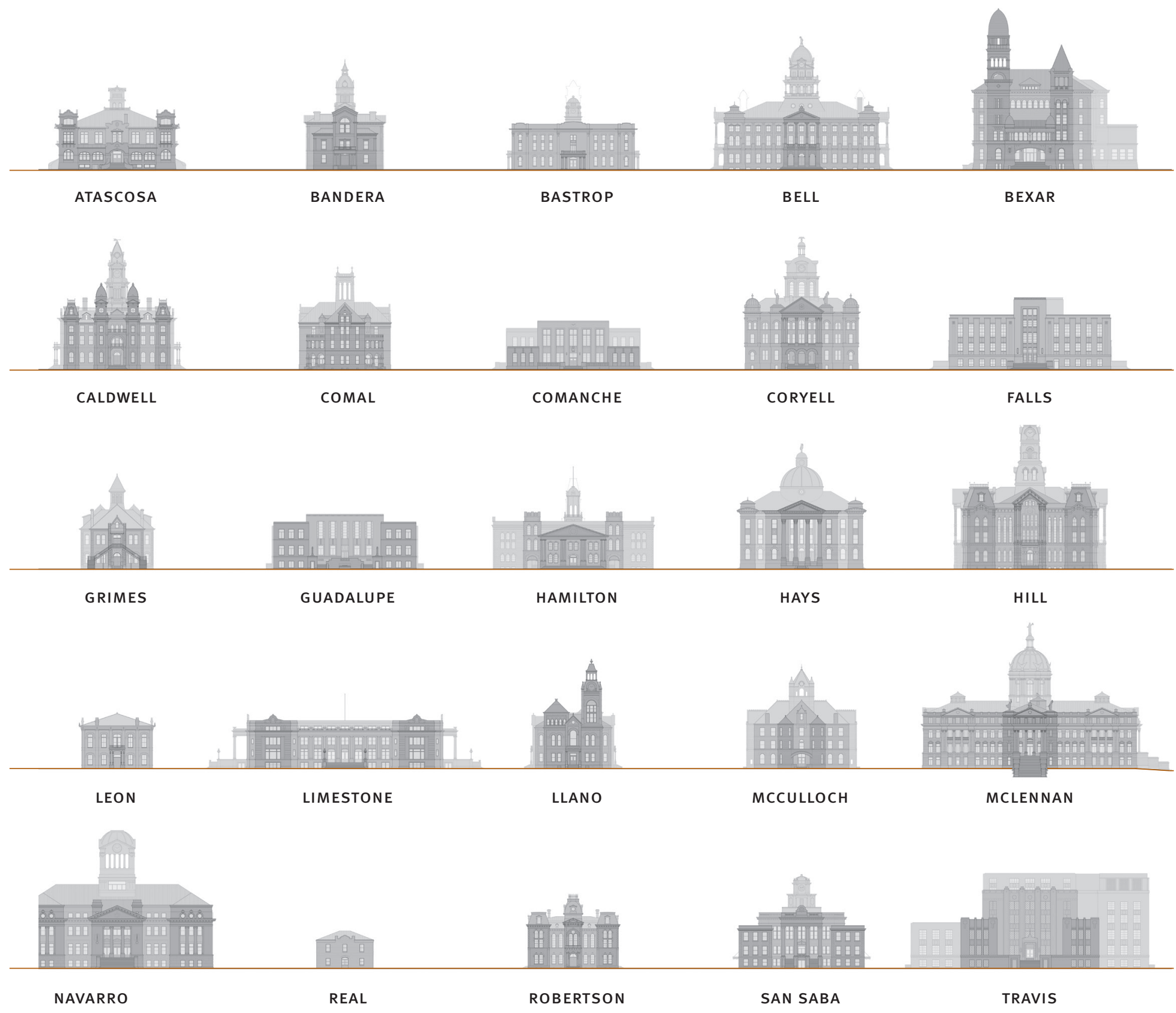




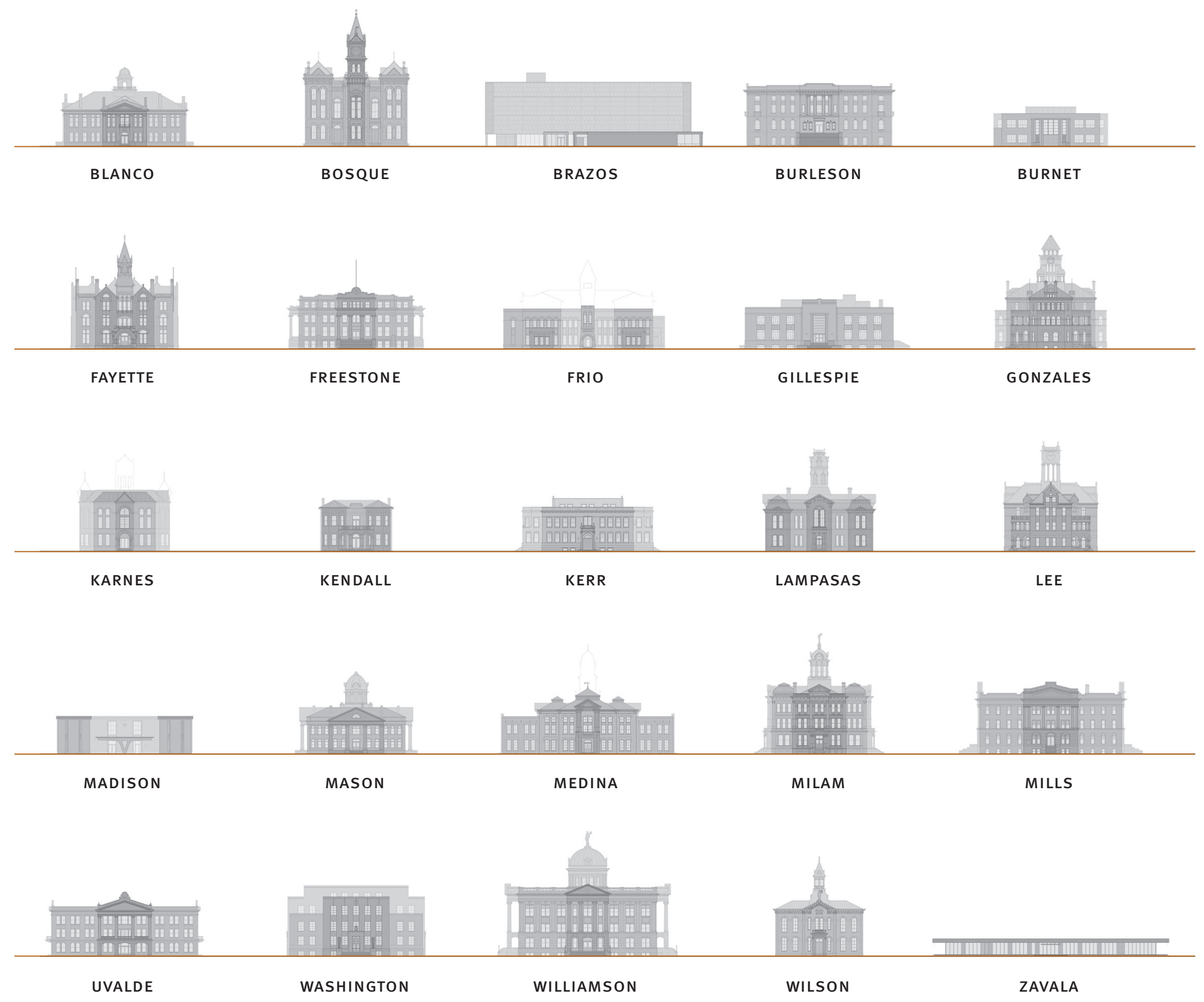




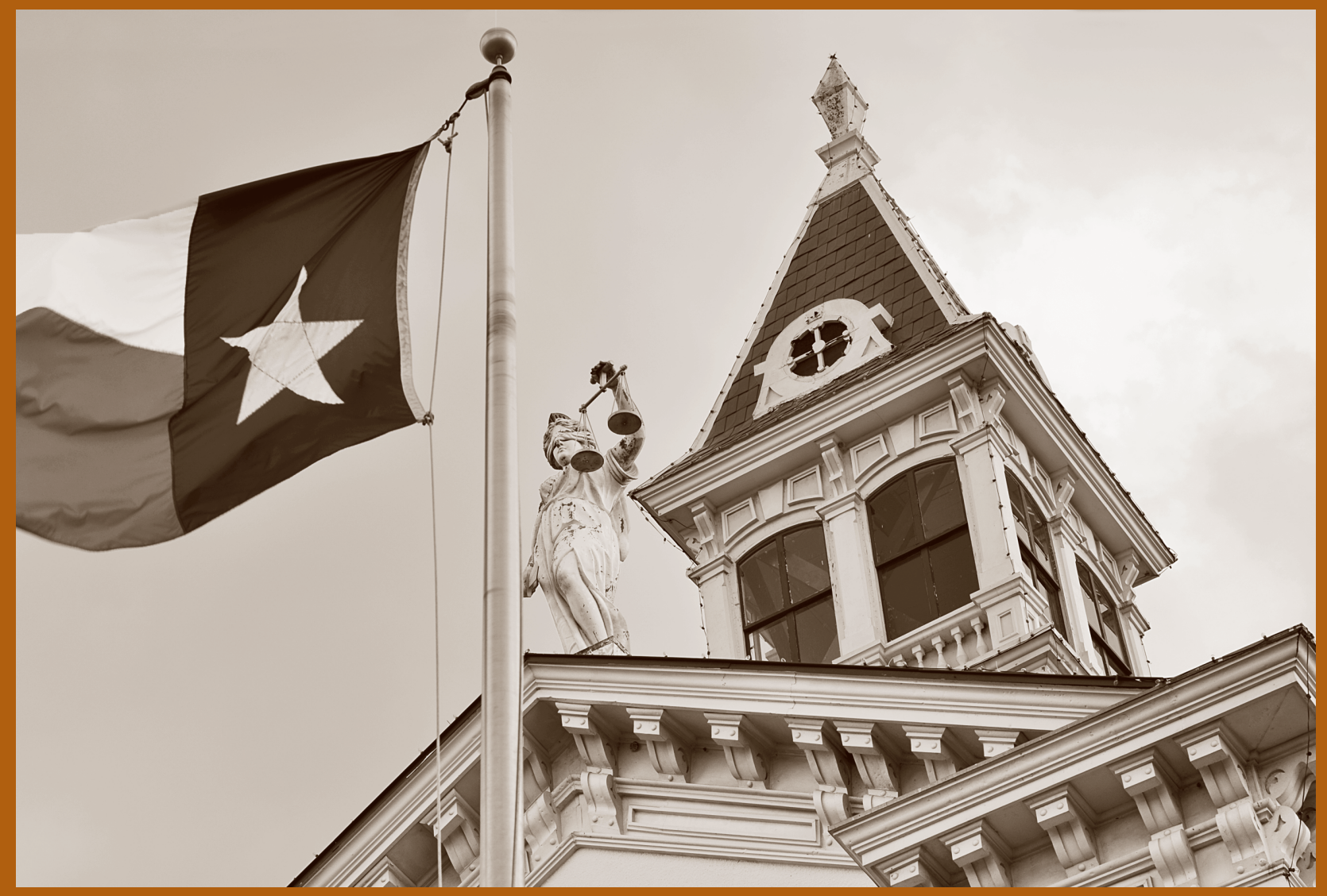

Wilson County Courthouse, 1884, Floresville, Texas

\author{
NUMBER TWENTY
}

Clifton and Shirley Caldwell Texas Heritage Series 
THE COURTHOUSES OF CENTRAL TEXAS 


\section{The Courthouses of Central Texas}

BRANTLEY HIGHTOWER

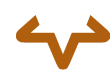

University of Texas Press AUSTIN

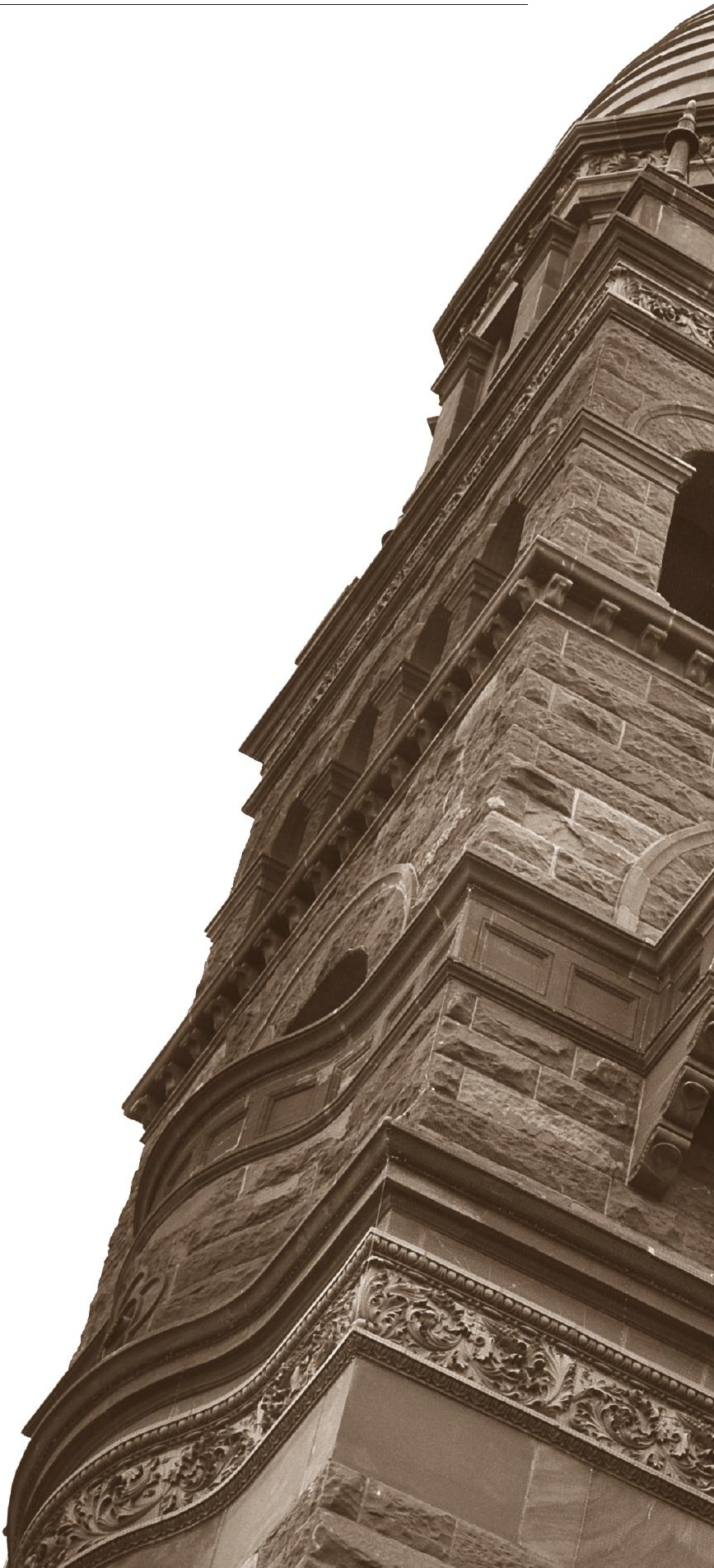




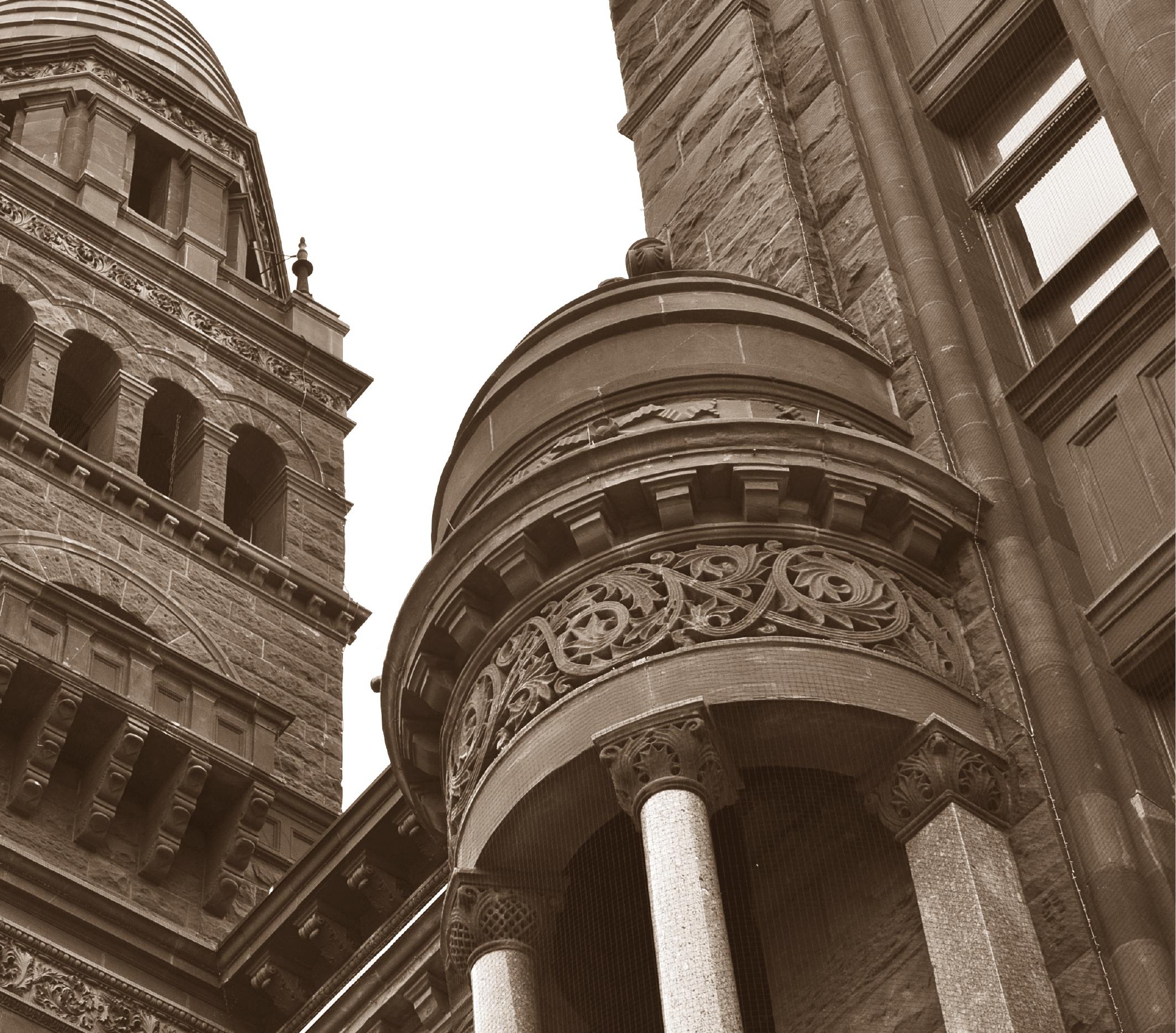


Publication of this work was made possible in part by support from Clifton and Shirley Caldwell and a challenge grant from the National Endowment for the Humanities.
Copyright $\left({ }^{\circ} 2015\right.$ by Brantley Hightower

All rights reserved

Printed in Singapore

First edition, 2015

Requests for permission to reproduce material from this work should be sent to:

Permissions

University of Texas Press

P.O. Box 7819

Austin, TX 78713-7819

http://utpress.utexas.edu/index.php/rp-form

The paper used in this book meets the minimum requirements of ANSI/NISO Z39.48-1992 (R1997) (Permanence of Paper).

\section{LIBRARY OF CONGRESS CATALOGING-IN-PUBLICATION DATA}

Hightower, Brantley, 1976-

The courthouses of central Texas / Brantley Hightower. - First edition.

pages $\quad \mathrm{cm} .-$ (Clifton and Shirley Caldwell Texas heritage series; number 20)

Includes bibliographical references and index.

ISBN 978-0-292-76294-7 (cloth : alk. paper)

1. Courthouses-Texas. 2. Texas-History. I. Title.

NA4472.T4H54 2015

$725^{\prime} .1509764-\mathrm{dc} 23$

2014017583

doi:10.7560/762947 
FOR SAMMY, OF COURSE. 


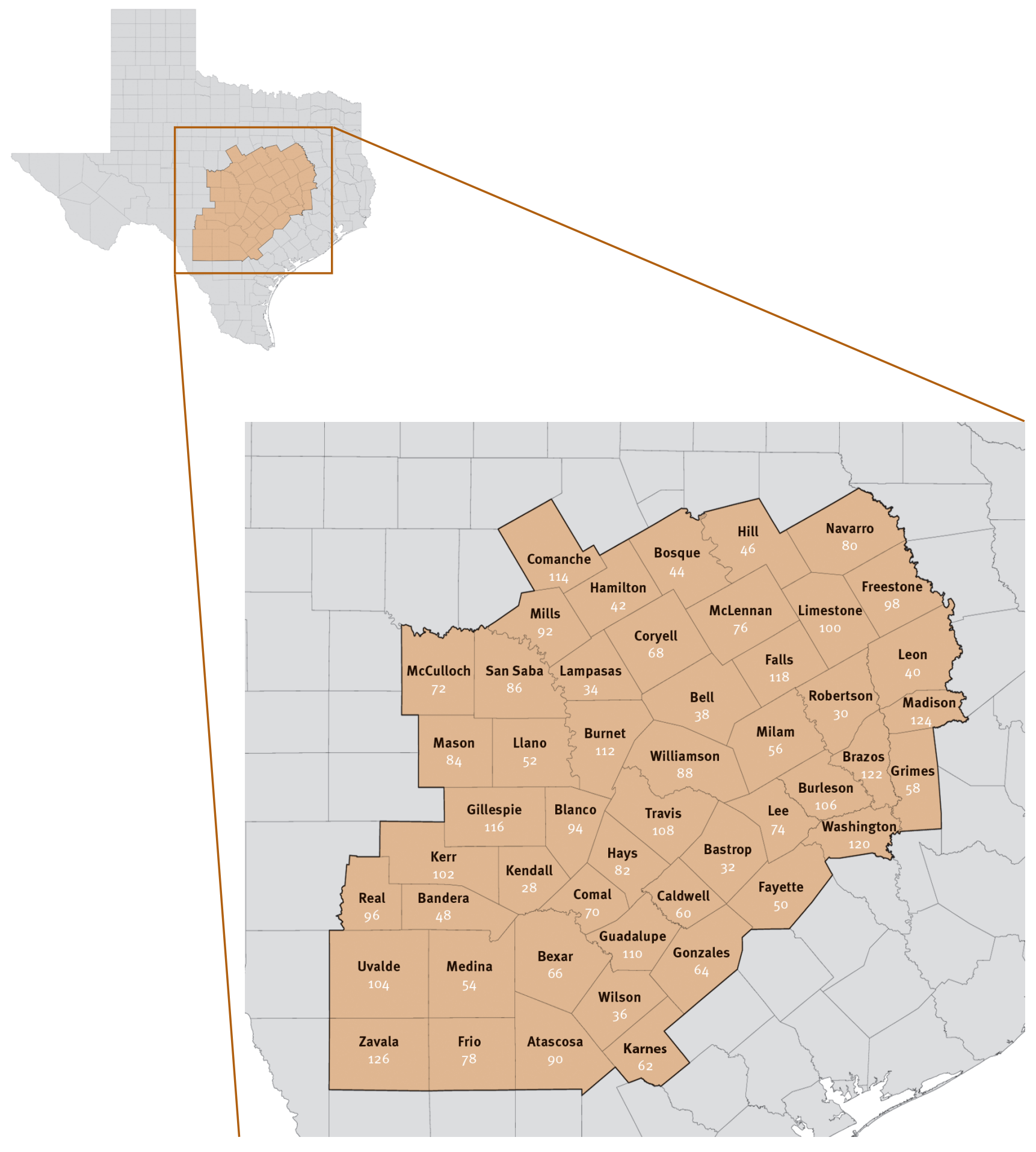

